\title{
ANALISIS STANDAR NASIONAL PENDIDIKAN TINGGI: STUDI KASUS DI UIN ANTASARI BANJARMASIN
}

\author{
Jejen Musfah', Budi Mulia ${ }^{2}$ \\ 1Program Studi Manajemen Pendidikan Islam, UIN Syarif Hidayatullah, Jakarta, Indonesia \\ ${ }^{2}$ Program Studi Sastra Indonesia, Universitas Pamulang, Tangerang, Indonesia \\ Email: jejen@uinjkt.ac.id ${ }^{1}$, dosen01549@unpam.ac.id ${ }^{2}$
}

DOI: http://doi.org/10.33650/al-tanzim.v4i2. 1052

\begin{tabular}{l|l|l} 
Received: March 2020 & Accepted: September 2020 & Published: September 2020 \\
\hline
\end{tabular}

\begin{abstract}
:
This study is to analyze the implementation of National Standard of Higher Education (Standar Nasional Perguruan Tinggi/SNPT) at Postgraduate Program of Islamic Education Departmen at UIN Antasari Banjarmasin, Kalimantan Selatan. This research uses a qualitative approach by collecting data through documentations, interviews, and observations. The technical data analysis is based on data collection, data reduction, data presentation, and drawing conclusions. The results showed that firstly, SNPT at Postgraduate Program of Islamic Education Departmen at UIN Antasari have not been properly met. Secondly, students have highly academic interest, but with low quality of graduate. Thirdly, research and writing's skills are really satisfied. Fourthly, the Islamic Education Departmen hasn't met the characteristics of good governance based institution with adequate facilities, good input and mature processes, and reliable education management. This study implies that Postgraduate Program of Islamic Education Departmen needs to advance learning facilities in the form of air conditioning and special rooms for lecturers, and to make learning evaluation. This Departmen needs to make strict selection and recrutment of students, and improvement of the learning process in order to produce good quality graduates. This Departmen has also to encourage the simultaneous research among lecturers.
\end{abstract}

Keywords: national standards, competencies, universities

\begin{abstract}
Abstrak:
Tujuan penelitian ini adalah menganalisis implementasi SNPT S2 PAI di UIN Antasari Banjarmasin, Kalimantan Selatan. Penelitian ini menggunakan pendekatan kualitatif. Pengumpulan data dilakukan melalui studi dokumen, wawancara, dan observasi. Teknis analisa data dilakukan dengan cara koleksi data, reduksi data, penyajian data, dan penarikan kesimpulan. Hasil penelitian ini menunjukkan bahwa; pertama, standar nasional PT Prodi S2 PAI UIN Antasari belum terpenuhi secara baik. Kedua, Minat mahasiswa sangat tinggi tetapi belum menghasilkan lulusan yang berkualitas karena inputnya pun lemah. Ketiga, kinerja penelitian dan penulisan dosen belum baik dan memuaskan. Keempat, Prodi S2 PAI tidak memenuhi ciri lembaga yang sehat, yaitu memiliki fasilitas yang memadai, input baik dan proses yang matang, dan pengelola pendidikan yang handal. Implikasinya, Prodi melengkapi fasilitas belajar berupa AC dan ruangan khusus dosen, dan melakukan evaluasi pembelajaran. Kedua, Prodi selektif dalam menerima mahasiswa, dan memperbaiki proses pembelajaran, sehingga menghasilkan mutu lulusan yang baik. Ketiga, Prodi mendorong dosen melakukan penelitian secara serius.
\end{abstract}

Kata Kunci: standar nasional, kompetensi, perguruan tinggi 


\section{PENDAHULUAN}

Sebelum pembukaan program Magister, Prodi Pendidikan Islam telah menyelenggarakan pendidikan konsentrasi Pendidikan Agama Islam (PAI) melalui kerjasama dengan Kementerian Agama (2008-2010). Magister PAI didirikan untuk guru PAI di sekolah (Pascasarjana, 2012). Berdasarkan SK Dirjen Pendis Kemenag RI No. 2085 Tahun 2013 tentang tranformasi konsentrasi menjadi Prodi, maka konsentrasi-konsentrasi studi pada Pascasarjana IAIN Antasari Banjarmasin berubah menjadi Prodi Akhlak dan Tasawuf, Hukum Ekonomi Syariah, Pendidikan Agama Islam (PAI), dan Manajemen Pendidikan Islam (MPI) (Pascasarjana, 2015). Selanjutnya, lahir S2 PBA dan Hukum Keluarga, S3 PAI dan Ilmu Syariah.

Visi Program studi S2 PAI UIN Antasari adalah menjadi pusat pendidikan dan pengembangan ilmu pendidikan agama Islam yang islami, unggul dan kompetitif pada tingkat nasional Tahun 2022. Misi Prodi adalah menyelenggarakan pembelajaran yang amanah, metodis dan profesional untuk menyiapkan magister pendidikan yang memiliki kompetensi khusus dalam Pendidikan Agama Islam.

Program Studi ini bertujuan untuk meningkatkan tenaga profesional yang memiliki kemampuan dalam mengelola, menganalisis, memecahkan persoalan-persoalan dalam pendidikan agama Islam dengan konsep-konsep pengembangan imu pendidikan berdasarkan nilai-nilai Islam. Sementara itu, tujuan khususnya meliputi; 1) Menghasilkan lulusan yang mampu mendidik calon guru/dan guru PAI Madrasah/Sekolah yang professional; 2) Menghasilkan lulusan yang ahli dalam bidang disiplin ilmu pendidikan agama Islam; 3) Meningkatkan tenaga pendidik yang profesional dalam bidang imu pendidikan agama Islam di Madrasah maupun sekolah dari jenjang dasar, menengah sampai dengan jenjang S1; 4) Meningkatkan temua penelitian dalam bidang kependidikan untuk mendukung pengembangan disiplin ilmu pendidikan agama Islam dan memecahkan masalah-masalah kependidikan; 5) Meningkatkan publikasi ilmiah dan pengabdian kepada masyarakat dalam bidang ilmu pendidikan agama Islam.

Riset tentang mutu pendidikan tinggi sudah banyak dilakukan, di antaranya; Bali (2017) yang menyatakan bahwa pendidikan tinggi dapat dikatakan berhasil jika mampu memberikan layanan sesuai harapan "pelanggan pendidikan" dan menghasilkan produk yang memuaskan (Asmawi, 2005), khususnya masyarakat pengguna jasa pendidikan (Kim \& Olson, 2016). Untuk mendapat mahasiswa dengan bibit yang terbaik, dapat dilakukan dengan sistem seleksi yang hanya mempertimbangkan mutu (Winarsih, 2017), bukan target jumlah mahasiswa kerja (Sulaiman \& Wibowo, 2016), sehingga output (lulusan) yang dihasilkan dapat diminati di pasar bursa tenaga (Iskandar, 2017). Kendala yang dihadapi dalam meningkatkan mutu pendidikan adalah; komitmen pimpinan (Do et al., 2020), jumlah tenaga auditor, dan kegiatan Sistem Penjaminan Mutu Internal (SPMI) menjadi rutinitas (Choiriyah et al., 2018). Berbeda dengan riset-riset sebelumnya, penelitian ini terfokus pada implementasi manajemen standar nasional perguruan tinggi pada program pascasarjana S2 PAI UIN Antasari Banjarmasin, Kalimantan Selatan. 


\section{METODE PENELITIAN}

Penelitian ini menggunakan pendekatan kualitatif, yakni menganalisis data yang berupa data-data tertulis atau wawancara secara langsung dari orang yang terlibat dalam penelitian ini (informan) serta perilaku yang diamati, sehingga dalam hal ini penulis berupaya mengadakan penelitian yang bersifat menggambarkan secara menyeluruh.

Pengumpulan data melalui metode observasi, wawancara, dan dokumentasi. 1) Observasi dilakukan di perpustakaan, ruang dosen, ruang pimpinan, ruang kelas, dan lingkungan kampus; 2) Wawancara dilakukan dengan direktur pascasarjana, ketua Prodi, dosen, mahasiswa, dan petugas perpustakaan; 3) Dokumen yang dikumpulkan adalah pedoman akademik, pedoman penulisan karya ilmiah, dokumen kurikulum. Penelitian dilakukan selama 8 hari (24 sampai 31 Juli 2018). Teknis analisa data dilakukan dengan cara koleksi data, reduksi data, penyajian data, dan penarikan kesimpulan.

\section{HASIL DAN PEMBAHASAN}

Berdasarkan hasil observasi, intrevie dan dokumentasi peneliti selama di lapangan, didapatkan bahwa implementasi Standar Nasional Pendidikan Tinggi (SNPT) pada pendidikan program pascasarjana S2 PAI UIN Antasari Banjarmasin berdasarkan Permenristekdikti RI No. 44 Tahun 2015, sebagai berikut;

\section{Standar Kompetensi Lulusan}

Berdasarkan UU No. 12 Tahun 2012 tentang Pendidikan Tinggi, lulusan magister diharapkan mampu mengamalkan dan mengembangkan ilmu pengetahuan dan/atau teknologi melalui penalaran dan penelitian ilmiah. Menurut Peraturan Pemerintah RI Nomor 8 tahun 2012 tentang KKNI dijelaskan sebagai berikut; 1) mampu mengembangkan IPTEK melalui riset, hingga menghasilkan karya inovatif dan teruji; 2) mampu memecahkan permasalahan bidang keilmuannya melalui pendekatan inter atau multidisipliner; 3) mampu mengelola riset dan pengembangan sehingga mampu emndapat pengakuan nasional maupun internasional.

Lulusan S2 PAI Antasari diharapkan menjadi pendidik, peneliti, atau manajer pendidikan. Mahasiswa diberi teori dalam bentuk tatap muka di kelas selama tiga semester. Untuk mencapai tujuan tersebut Prodi menyiapkan program perkuliahan, penulisan proposal, dan penulisan tesis. Pencapaian SKL tidak mudah karena banyak kendala.

Menurut Mahyudin (2018), penulisan proposal di akhir semester 2 dibolehkan karena biasanya setelah semester empat dan kembali ke daerahnya mahasiswa melupakan tesis karena terlena pekerjaan atau keluarga. Akhirnya, pada semester akhir mereka buru-buru menulis tesis dan minta segera disetujui. Tesisnya tidak sesuai standar. Kelulusan mereka karena dikasihani Prodi dan dosen. Seorang mahasiswa kelas khusus, Lisa (2018) menjelaskan, "Rumah saya di Kalimantan Tengah memerlukan 10 jam ke kampus. Seminggu saya di kampus, tiga minggu saya pulang." Mahasiswa umumnya sudah bekerja. 
Kewajiban memiliki skors TOEFL dan TOAFL tertentu belum diterapkan di S2, karena pertimbangan mahasiswa banyak yang berasal dari daerahdaerah dan kompetensi mereka. Mahyudin (2018) menjelaskan, program S2 ini merupakan sarana dakwah bagi peningkatan kompetensi sumber daya daerah agar kelak mereka bisa bersaing. Akan tetapi, mulai tahun ini, sebelum lulus mereka harus punya skors 450 TOEFL dan TOAFL. Kecuali pada semester satu, setiap mahasiswa wajib belajar bahasa Arab dan Inggris klasikal non SKS.

Untuk mendorong budaya menulis, disediakan dana penelitian bagi mahasiswa. Pada 2015, ditetapkan bantuan penelitian mahasiswa sebanyak 20 judul, di mana setiap judul dilakukan oleh tiga mahasiswa, dengan biaya perjudul Rp 2.400.000 rupiah.

\section{Standar Isi Pembelajaran}

Beban Sistem Kredit Semester (SKS) dalam perkuliahan yang dilaksanakan di program magister berkisar antara 44-50 SKS. Pengambilan mata kuliah persemester sebanyak-banyak 15 sks (di luar mata kuliah remedial) agar mahasiswa dapat mendalami mata kuliah seoptimal mungkin dengan cara banyak membaca, menulis, mengkritisi dan melakukan penelitian (Pascasarjana, 2016). Silabus atau RPS sudah sejak 2016 mengacu pada KKNI, tetapi dokumen kurikulum KKNI S2 PAI secara utuh belum dimiliki. Menurut Salamah (2018), "Penyusunannya akan dimulai tahun 2018 ini".

Seorang alumni yang saat ini menjadi dosen swasta, Muhamad (2018) menyatakan, calon mahasiswa S2 PAI sebaiknya dites kefasihan mengaji karena tidak cukup pandai beretorika dalam berdiskusi, tetapi masyarakat menilai mereka orang yang alim, mampu ceramah, dan menjadi imam.

Berikut tabel struktur mata kuliah S2 PAI selama empat semester.

Tabel 1 : Sebaran Mata Kuliah S2 PAI IAIN Antasari Banjarmasin

\begin{tabular}{c|l|c|c}
\hline NO & MATA KULIAH & SKS & SMT \\
\hline 1 & Qawa'id al-Tafsir & 3 & I \\
\hline 2 & Qawa'id al-Tahdits & 3 & I \\
\hline 3 & Sejarah Pemikiran dan Peradaban Islam & 3 & I \\
\hline 4 & Filsafat Ilmu (Integrasi Ilmu) & 3 & I \\
\hline 5 & Metode Penelitian & 3 & II \\
\hline 6 & Dasar, Prinsip, dan Tujuan Pendidikan Agama Islam & 3 & III \\
\hline 7 & Kepemimpinan dalam Lembaga Pendidikan Islam & 3 & II \\
\hline 8 & Pendalaman Materi Pendidikan Agama Islam & 3 & II \\
\hline 9 & Telaah Kurikulum Pendidikan Agama Islam & 3 & III \\
\hline 10 & Evaluasi Pendidikan & 3 & III \\
\hline 11 & Teori dan Praktik Belajar Mengajar Pendidikan Agama & 3 & I \\
\hline 12 & Islam & 2 & III \\
\hline 13 & Psikologi Pendidikan Islam * ${ }^{*}$ & 2 & II \\
\hline 14 & Sosiologi Pendidikan Islam * & 2 & II \\
\hline 15 & Model-Model Pembelajaran* & 2 & III \\
\hline 16 & Pengembangan Kurikulum Pendidikan Agama Islam* & \\
\hline
\end{tabular}




\begin{tabular}{c|l|c|c}
\hline 17 & Seminar Proposal & 2 & III \\
\hline 18 & Teknologi Informasi (IT) dalam Pendidikan Agama Islam & 2 & II \\
\hline 19 & Tesis & 6 & IV \\
\hline
\end{tabular}

Tawaran mata kuliah dalam buku pedoman akademik tahun 2016 seperti Tabel 1 ini berbeda dengan struktur mata kuliah pada proposal pengajuan Prodi S2 PAI tahun 2012. Misalnya, Ulumul Hadits menjadi Qawaid al-Hadits, Ulumul Quran menjadi Qawaid al-Tafsir, Sejarah Pemikiran dan Peradaban Islam pada awalnya merupakan dua mata kuliah.

\section{Standar Proses Pembelajaran}

Berdasarkan waktu perkuliahan, ada tiga pilihan: 1) kelas reguler. Perkuliahan di kelas (terjadwal) selama tiga semester dengan kuliah pada hari Senin hingga hari Jumat; 2) kelas eksekutif. Perkuliahan di kelas (terjadwal) selama empat semester dengan kuliah pada hari Jumat dan hari Sabtu; 3) kelas khusus. Perkuliahan di kelas (terjadwal) selama lima semester. Kuliah full satu minggu, libur tiga minggu. Kelas khusus bagi mahasiswa yang rumahnya jauh dari kampus.

Perkuliahan oleh dosen-dosen berkualifikasi doktor dan profesor lulusan perguruan tinggi terkemuka di dalam dan luar negeri. Sistem perkuliahan menekankan pada pendalaman dan perluasan wawasan akademik. Mahasiswa dilatih berpikir kritis-analitis, rasional, mandiri dan terbuka melalui penelitian, seminar kelas dan interactive learning. Masa studi mahasiswa adalah empat tahun akademik. Mahasiswa yang tidak selesai dalam waktu yang ditentukan tersebut dinyatakan gugur (drop out).

Kegiatan proses perkuliahan dirancang dengan mewajibkan setiap mahasiswa menyajikan makalah dalam bentuk seminar kelas, membuat laporan buku/ jurnal, laporan kerja lapangan/ proyek penelitian dan selanjutnya memperbaikinya setelah mendapatkan tanggapan dari peserta seminar dan dosen. Kegiatan dalam bentuk karya tulis harus menggunakan referensi termutakhir. Jurnal maksimal lima tahun terakhir, buku 10 tahun terakhir (Pascasarjana, 2016). Perkuliahan dilaksanakan oleh tim dosen dengan rombongan belajar maksimal 25 orang.

\section{Standar Penilaian Pembelajaran}

Penilaian akademik mahasiswa mencakup kehadiran perkuliahan, tugas, Ujian Tugas Semester (UTS), Ujian Akhir Semester (UAS), dan penulisan tesis. Kriteria penilaian mata kuliah dan tesis menggunakan standar umum, yaitu memakai A +, A -, B +, B -, dan seterusnya.

Setiap judul tesis harus disetujui oleh Dewan Pertimbangan Akademik (DPA) yang terdiri dari unsur Kaprodi, Profesor, dan Doktor. Penilaian kelayakan proposal diujikan pada forum sidang ujian proposal. Penilaian kelulusan mahasiswa disyaratkan hasil penelitian tesis dapat diterbitkan pada jurnal nasional terakreditasi atau terindeks (Pascasarjana, 2016). 


\section{Standar Dosen dan Tenaga Kependidikan}

Berdasarkan pengajuan SK dosen home base S2 PAI, diusulkan 7 orang dosen, yaitu 6 doktor dan satu orang profesor. Semuanya statusnya sebagai dosen PNS. Menurut Salamah (2018) penentuan dosen tersebut tidak mudah karena Prodi S1 PAI juga menginginkan dosen bergelar profesor dan doktor yang produktif agar profil Prodi atau borangnya bagus. Masalahnya, satu orang dosen hanya boleh berada di satu Prodi S1, S2, atau S3, meskipun Prodi yang sama.

Dalam pelaksanaan tugas, Direktur dibantu oleh pengelola Prodi dan unsur pelaksana administrasi: koordinator administrasi, umum, akademik dan kemahasiswaan, keuangan, dan perpustakaan. Pascasarjana memiliki satu orang staf akademik dan kemahasiswaan yang menangani enam Prodi S2 dan dua Prodi S3. Menurut Salmah (2018) perlu penambahan staff akademik agar pelayanan kepada mahasiswa lebih baik lagi. Pada waktu-waktu tertentu, Ketua Prodi melayani konsultasi judul tesis mahasiswa dari pagi sampai sore.

\section{Standar Sarana dan Pra-Sarana Pembelajaran}

Ruang kelas cukup tetapi perlu penambahan seiring penambahan jumlah mahasiswa. Pada 2017, ruang mahasiswa dijadikan kelas. Ruang kelas sebagian memakai pendingin ruangan dan sebagiannya kipas angin. Ruang atau meja dosen tidak ada di pascasarjana tetapi ada di fakultas masingmasing. Terdapat perpustakaan khusus pascasarjana. Tidak ada khusus Prodi. Mahasiswa mengunjungi perpustakaan khususnya saat membuat makalah dan tesis. Pinjam meminjam buku dilakukan secara daring.

Terdapat gedung dan fasilitas belajar representatif (10 ruang kuliah), 10 ruang profesor, internet Wi-Fi dan Wifi.id, koleksi perpustakaan memadai, area parkir luas, guest house, klinik kesehatan, auditorium, musola, masjid, gedung olahraga, dan lingkungan yang kondusif. Gedung-gedung kampus dibangun di atas rawa yang diuruk tanah, pasir, dan batu.

Suasana kampus di luar gedung pada akhir Juli cukup panas, sementara tidak banyak pohon rindang untuk berteduh. Demikian pula dari pintu masuk hingga ke dalam kampus jalanan terasa gersang karena tidak ditumbuhi pohon besar padahal tanahnya memadai.

\section{Standar Pengelolaan Pembelajaran}

Pascasarjana memiliki renstra yang segera diperbaiki terkait peralihan IAIN ke UIN (2017). Prodi merumuskan program kerjanya selama setahun di tingkat pascasarjana. Pedoman akademik dan tesis ada di tingkat pascasarjana. Lembaga penjaminan mutu ada di tingkat universitas sedangkan di pascasarjana ada gugus penjamin mutu yang dirangkap oleh Sekprodi. Evaluasi dosen dilakukan oleh mahasiswa secara daring setiap semester. Masalahnya, kadang datanya diolah kadang tidak. Hasilnya disampaikan ke dosen pada saat rapat dosen dan sidang DPA.

Jaminan terhadap proses akademik dilaksanakan melalui; 1) daftar hadir mengajar dosen; 2) daftar hadir mahasiswa (minimal 75 persen kehadiran perkuliahan); 3) tersedianya Rencana Pembelajaran Semester (RPS) dosen dan kontrak belajar; 4) angket penilaian mahasiswa terhadap kinerja dosen yang 
meliputi akademik, pedagogik, dan kepribadian (Pascasarjana, 2012).

Untuk menjamin mutu pelayanan administrasi dilakukan dengan memenuhi: pertama, daftar hadir karyawan; kinerja karyawan berdasarkan SOP; kedua, angket kepuasaan mahasiswa terhadap kinerja karyawan. Untuk menjaga jaminan mutu terhadap alumni dilakukan melalui; a) memperketat seleksi calon; b) memperketat prosedur-prosedur bimbingan sesuai dengan pedoman akademik.

Materi ujian adalah bahasa Arab (tertulis), Inggris (tertulis), TPA, dan wawancara. IPK minimal 3,00 (skala 4) atau 4,00 (skala 5). Calon mahasiswa melakukan pendaftaran secara daring melalui laman pasca.uinantasari.ac.id/pmb. Tidak perlu menyiapkan proposal tesis, kecuali program doktor.

Syarat ujian tesis adalah mahasiswa harus menyelesaikan seluruh mata kuliah, lunas biaya semester, dan persetujuan tesis dari dua pembimbing. Dalam buku Pedoman Akademik ditulis bahwa sebelum ujian mahasiswa harus memiliki skor TOEFL dan TOAFL 425 dan 400, tetapi belum dilaksanakan. Menurut Kaprodi dan dosen (2018), hal ini dikarenakan kompetensi bahasa mahasiswa masih lemah. Mereka belum siap seandainya diterapkan, tetapi mulai tahun 2018 ini akan diterapkan. Ujian tesis dilakukan dalam satu tahap. Pada program pascasarjana S2 PAI UIN Jakarta, tesis diujikan dalam dua tahap.

Selain mendapat dosen pembimbing tesis, mahasiswa mendapat satu pembimbing proposal. Setelah disetujui pembimbing, proposal akan diujikan tiga penguji yang terdiri dari ketua penguji, penguji utama, dan anggota penguji. Persetujuan akumulasi kemajuan tesis mencakup: proposal, pengumpulan data, pengolahan data, penulisan yang mencakup: bab I, bab II, bab III, bab IV, bab V, kesimpulan dan saran, abstrak, dan pelengkap (daftar isi, daftar tabel, daftar pustaka, dll). Jika semua sudah terisi maka bisa diuji atas persetujuan pembimbing I, pembimbing II, dan Ketua Prodi yang dibuktikan dengan buku bimbingan proposal dan tesis. Semua blanko surat menyurat Pascasarjana IAIN Banjarmasin bisa diunduh pada link http://idr.iainantasari.ac.id/3598/.

Penyelenggaraan S2 PAI di Pascasarjana bukan di fakultas, karena sarana prasarana di fakultas belum memadai. Belum ada sama sekali wacana memindahkan S2 ke fakultas. Di sini ada 8 prodi pascasarjana sehingga pembagian dosen sedikit masalah karena tidak ada perekrutan dosen baru.

\section{Standar Pembiayaan Pembelajaran}

Pendanaan Prodi berasal dari mahasiswa dan beasiswa dari Kemenag untuk kelas beasiswa-tidak tetap. Perincian biaya S2 PAI sebagai berikut. Pembinaan dan pengembangan Rp 500.000 dibayar sekali pada saat daftar ulang. Keanggotaan perpustakaan Rp 100.000. Pelayanan bahasa asing Rp 600.000. Khusus bagi mahasiswa yang pendidikannya tidak linier, biaya matrikulasi Rp 1.300.000. Biaya kuliah Rp 3.750.000 rupiah. Penyusunan RABPB Prodi dilakukan bersama pada level pascasarjana. 


\section{Kinerja Penelitian Dosen}

Dosen wajib melakukan penelitian atas biaya sendiri atau pihak luar. Berikut adalah penelitian, jurnal, buku, dan prosiding yang dilakukan tujuh dosen home base S2 PAI selama 2015, 2016, 2017, sebagai berikut;

Tabel 2 : Kinerja Penelitian Dosen S2 PAI di UIN Antasari

\begin{tabular}{|c|c|c|c|c|c|c|c|c|c|c|c|c|}
\hline \multirow{2}{*}{ Nama } & \multicolumn{4}{|c|}{2015} & \multicolumn{4}{|c|}{2016} & \multicolumn{4}{|c|}{2017} \\
\hline & 1 & 2 & 3 & 4 & 1 & 2 & 3 & 4 & 1 & 2 & 3 & 4 \\
\hline Ahdi Makmur & & & & & & & & 1 & 1 & & & \\
\hline Abdul Basir & & & & & 1 & & & 2 & & & & 1 \\
\hline Fahmi Riady & & 2 & & 1 & & 2 & & & & 2 & & \\
\hline Hilmi Mizani & & & & & 1 & & & & & & & \\
\hline Mahyuddin Barni & & & & & 1 & 1 & & & & & 1 & \\
\hline Ridhahani Fidzi & & & & & 1 & 1 & & 2 & 1 & 1 & & \\
\hline Salamah & & & & 1 & 1 & 1 & & 1 & 1 & & & 1 \\
\hline
\end{tabular}

Keterangan:

$1=$ penelitian $2=$ jurnal $3=$ prosiding $4=$ buku

Penelitian ilmu pengetahuan terapan pada 2017, sebesar Rp 50 juta, setiap tim terdiri dari 3 dosen; 1) Ahdi Makmur dengan judul "Diaspora Pejuang dan Ulama Banjar di Asia Tenggara"; 2) Ridhahani Fidzi dengan judul "Diaspora Muhammadiyah di Kalimantan Selatan; 3) Salamah dengan judul "Pengembangan Model Pendidikan Keterampilan Hidup pada Kelompok Ponpes Se Kota Banjarmasin".

Penelitian ilmu pengetahuan terapan pada 2016, sebesar Rp 36 juta, setiap kelompok 3 dosen, diantaranya; 1) Ridhahani Fidzi dan Ahdi Makmur dengan judul "Pengaruh Pemberitaan Media Massa terhadap Kesadaran Revolusi Mental Birokrasi dalam Pelayanan Publik di Kalimantan Selatan"; 2) Helmi Mizani dengan judul "Implementasi Pendidikan Pra Nikah di Kalimantan Selatan".

Penelitian kelompok dosen pengembangan Prodi 2016 diantaranya; 1) Abdul Basir dengan judul "Pembentukan Karakter Kepemimpinan Siswa melalui Sekolah Alam"; 2) Salamah dengan judul "Pengembangan Model Pembelajaran Berbasis Pendidikan Lingkungan dengan Lahan Basah pada MI di Kota Banjarmasin". Secara akumulatif, berikut tabel kinerja penelitian dosen.

\section{Minat Mahasiswa}

Minat masyarakat kuliah S2 PAI di UIN Antasari cukup tinggi. Setiap tahun minimal membuka tiga kelas. Promosi dilakukan melalui kunjungan ke sekolah di daerah Kalimantan. Tidak ada strategi khusus untuk merekrut mahasiswa karena masyarakat sudah mengenal dengan baik.

Menurut mahasiswa, alasan memilih Pascasarjana Antasari Banjarmasin adalah status negeri, kualitas dosen, dan kelengkapan sarana pra sarana. Setelah menjalani kuliah, mereka puas dengan kompetensi dan pengajaran dosen. Jumlah mahasiswa tergambar dalam tabel berikut; 
Tabel 3 : Jumlah Mahasiswa S2 PAI UIN Antasari

\begin{tabular}{lcccccc}
\hline Angkatan & $\begin{array}{c}\text { Jmlh } \\
\text { mhs }\end{array}$ & Alumni & Daftar & $\begin{array}{c}\text { Lulus } \\
\text { masuk }\end{array}$ & Aktif & $\begin{array}{c}\text { Non- } \\
\text { aktif }\end{array}$ \\
\hline 2012 & 57 & 28 & & & 5 & 24 \\
\hline 2013 & 76 & 42 & & & 16 & 18 \\
\hline 2014 & 79 & 23 & 97 & 82 & 36 & 20 \\
\hline 2015 & 112 & 34 & 123 & 114 & 68 & 10 \\
\hline 2016 & 86 & 3 & 98 & 96 & 79 & 4 \\
\hline 2017 & 84 & 0 & 96 & 90 & 84 & 0 \\
\hline
\end{tabular}

Sejak 2014, Prodi PAI telah meluluskan 137 lulusan, dengan rata-rata IPK di atas 3.00. IPK terendah adalah 3.14 yang lulus pada 2014, sedangkan IPK tertinggi 3.71 yang lulus pada 2015. Lulusan pertama adalah 22 Oktober 2014, sedangkan lulusan terakhir 29 Maret 2018.

Minat mahasiswa kuliah S2 di UIN Antasari sangat tinggi. Tahun 2015 menerima 112 mahasiswa, tahun 2016 menerima 86 mahasiswa, dan tahun 2017 menerima 84 mahasiswa. Akan tetapi kualitas mahasiswa masih rendah. Misalnya dalam kemampuan bahasa asing. Kelulusan mahasiswa bukan karena tesis mereka bagus atau mereka melahirkan karya inovatif dan kreatif, tetapi sebagian karena kemurahan hati dosen. Pembukaan S2 di kampus ini bertujuan meningkatkan sumber daya manusia daerah. Kuliah S2 diharapkan mampu membuka wawasan dan mengubah cara berpikir mahasiswa. Wani \& Mehraj (2014) menjelaskan bahwa kualitas berarti tingkat keunggulan karena menunjukkan pada karakter yang khas dan esensial, yang membuat sesuatu menjadi unik dan terbaik dari jenisnya.

Kampus sering dalam posisi dilematis antara kuantitas dan kualitas mahasiswa. Menerima sebanyak mungkin mahasiswa walaupun kualitasnya rendah. Jika berorientasi pada mutu maka mahasiswa yang diterima akan sedikit. Input mahasiswa yang rendah akan berpengaruh pada mutu lulusan. Meskipun prosesnya bagus, dosen dan mahasiswa akan mengalami kesulitan karena sejak awal kualitas mahasiswa rendah.

Menurut Sanaky (2008), pendidikan akan menjadi sia-sia apabila mutu proses dan lulusannya rendah. Oleh karena itu jika ingin menghasilkan kualitas lulusan yang baik maka kampus harus menerima kualitas input yang bagus pula disertai proses yang baik (Kesici \& Çavuş, 2019). Kualitas dosen dan fasilitas belajar yang memadai akan memengaruhi proses belajar yang baik.

Kebijakan home base dosen bahwa satu dosen hanya boleh berada di satu Prodi tidak tepat dan memberatkan kampus. Jumlah dosen di kampus sangat terbatas, apalagi yang berpangkat guru besar dan doktor. Mereka menjadi rebutan antara Prodi S1 PAI, S2 PAI, dan S3 PAI, karena akan berpengaruh kepada profile Prodi terutama pada saat akan akreditasi. Karena itu, seharusnya kebijakan home base ini ditinjau ulang. Sururin (2017) mencatat, mayoritas program studi di lingkungan PTKI terakrediatsi C, dan mayoritas Institusi/Perguruan Tinggi di bawah PTKI status akreditasinya C. 
Rata-rata dosen mengajar di lebih satu Prodi bahkan sebagian mengajar di kampus yang berbeda. Artinya dosen memiliki waktu lebih untuk bisa mengajar lebih dari satu Prodi dan lebih dari satu kampus. Karena itu seharusnya home base dosen bisa lebih dari satu Prodi, dan bisa di beda kampus. Kebijakan home base saat ini lebih menitikberatkan pada kuantitas bukan pada kualitas dan realitas ketersediaan dan kemampuan dosen dalam mengajar.

Mutu pelayanan mahasiswa dan dosen tidak menjadi prioritas karena hanya ada satu staf untuk enam Prodi S2 dan dua Prodi Doktor. Salah satu dampaknya adalah Ketua Prodi dan Sekretaris Prodi sering mengerjakan halhal administratif dibanding membaca dan menulis. Waktu mereka di kampus dihabiskan untuk rapat dan pekerjaan administratif dibanding pengembangan akademik dan keilmuan. Kondisi ini terjadi hampir di semua pascasarjana, di mana jumlah mahasiswa dan dosen tidak sebanding dengan jumlah staf.

Penyebab umum rendahnya kualitas pendidikan dapat muncul dari berbagai sumber. Ini dapat mencakup desain kurikulum yang buruk, bangunan yang tidak sesuai dan tidak dirawat dengan baik, lingkungan kerja yang buruk, sistem dan prosedur yang tidak sesuai, jadwal waktu yang kurang kreatif, kurangnya sumber daya yang diperlukan, dan kurangnya pengembangan staf (Sallis, 2012).

Ciri lembaga pendidikan yang sehat memiliki fasilitas yang memadai, luaran siap terjun ke pasar kerja, input baik dan proses yang matang, kerjasama dengan pemerintah (Asmawi, 2005), dunia usaha dan dunia industri, dan pengelola pendidikan yang handal (Sayidah et al., 2019). Digitalisasi pelayanan akademik dan nonakademik mengurangi kebutuhan akan tenaga staf, tetapi dalam dunia pendidikan, pelayanan staf yang kompeten dan ramah merupakan kunci terciptanya kenyamanan mahasiswa dan kelancaran mereka dalam menyelesaikan kuliah (Kaewngam et al., 2019). Jumlah staf yang tidak memadai akan menurunkan kualitas layanan kepada mahasiswa dan dosen. Kampus menyediakan staf yang cukup walaupun konsekuensinya biaya bertambah. Menurut Noor (2020), permasalahan penganggaran yang relatif masih minim dapat mempengaruhi optimalisasi realisasi rencana kegiatan yang telah diagendakan. Khan et al., (2018) menjelaskan pemerintah harus meningkatkan anggaran untuk pendidikan sehingga lebih banyak fasilitas yang dapat diperkenalkan tentang pendidikan".

Kinerja penulisan karya tulis ilmiah dosen, baik penelitian, artikel, buku, maupun prosiding, tidak bagus karena pada 2015 hanya ada 4 karya ilmiah, tahun 2016 ada 16, dan 2017 terdapat 9 karya ilmiah. Padahal sumber dana penelitian ada di Kemenag dan kampus. Kecuali itu, sumber karya ilmiah bisa diolah dari tesis atau disertasi mahasiswa bimbingan. Apabila ingin meningkatkan peran dosen dalam penjaminan mutu di PT maka perlu dikembangkan kepemimpinan visioner (Sumardjoko, 2010), budaya orang yang mantap, dosen-dosen kompeten, dan memiliki motivasi berprestasi yang tinggi (Yinka, 2015).

Data karya ilmiah atau penelitian dosen di atas tidak sesuai kenyataan karena setiap dosen wajib melakukan penelitian minimal setahun sekali; satu judul penelitian bisa digunakan dua semester untuk syarat pembayaran 
tunjangan profesi dosen atau sertifikasi. Masalahnya, tidak semua dosen mengembangkan hasil penelitian menjadi artikel atau buku. Misal, tesis yang ditulis mahasiswa dengan bimbingan yang serius dari dosen bisa dikembangkan menjadi artikel bahkan buku. Hal ini tidak terjadi karena kualitas tesis yang rendah oleh sebab kualitas mahasiswa rendah dan/atau kualitas bimbingan yang tidak serius. Dosen mempertimbangkan penerbitan artikel atau buku yang ditulis bersama dengan mahasiswa karena kualitas keduanya akan memengaruhi nama baiknya.

\section{KESIMPULAN}

Standar nasional PT Prodi S2 PAI UIN Antasari belum terpenuhi secara baik, misalnya fasilitas belajar berupa AC dan ruangan khusus dosen, dan evaluasi pembelajaran. Jumlah mahasiswa S2 PAI setiap tahunnya sesuai kuota yaitu 3 kelas. Minat mahasiswa sangat tinggi tetapi belum menghasilkan lulusan yang berkualitas karena inputnya pun lemah. Kinerja penelitian dan penulisan dosen belum baik dan memuaskan. Prodi S2 PAI ini tidak memenuhi ciri lembaga yang sehat, yaitu memiliki fasilitas yang memadai, input baik dan proses yang matang, dan pengelola pendidikan yang handal. Kuantitas belum tentu menunjukkan kualitas mahasiswa jika tidak didukung fasilitas, input, proses, dan pengelolaan yang baik. Penelitian ini tidak mengkaji secara mendalam kurikulum, evaluasi, dan pembiayaan Prodi S2 PAI UIN Antasari, sehingga bisa diteruskan oleh peneliti selanjutnya.

\section{DAFTAR PUSTAKA}

Asmawi, M. R. (2005). Strategi Meningkatkan Lulusan Bermutu di Perguruan Tinggi. Makara, Sosial Humaniora, 9(2), 66-71.

Bali, M. M. E. I. (2017). Perguruan Tinggi Islam Berbasis Pondok Pesantren. AlTanzim: Jurnal Manajemen Pendidikan Islam, 1(2), 1-14.

Choiriyah, S., Kumaidi, \& Kartowagiran, B. (2018). Developing Delta Internal Quality Assurance to Evaluate the Quality of Indonesian Islamic Universities. Journal of Social Studies Education Research, 9(3), 177-197.

Do, D.-T., Le, C.-L., \& Giang, T.-V. (2020). European Journal of Educational Research. European Journal of Educational Research, 9(2), 499-509. https:/ / doi.org/10.12973/eu-jer.9.2.499

Iskandar. (2017). Improving the Quality of Academic Services through Implementation of Internal Quality Assurance System in State Institute of Islamic Studies STS Jambi. Journal of Education and Practice, 8(3), 57-63.

Kaewngam, A., Chatwattana, P., \& Piriyasurawong, P. (2019). Supply Chain Management Model in Digital Quality Assurance for ASEAN University Network Quality Assurance ( AUN - QA ). Higher Education Studies, 9(4), 12-20. https://doi.org/10.5539/hes.v9n4p12 
Kesici, A. E., \& Çavuş, B. (2019). University Life Quality and Impact Areas. Universal Journal of Educational Research, 7(6), 1376-1386. https://doi.org/10.13189/ujer.2019.070605

Khan, U. R., Khan, S., Aslam, S. M., \& Mateen, S. (2018). Total Quality Management in Education. International Journal of Science and Business, 2(2), 182-197.

Kim, E. P., \& Olson, M. (2016). Exemplary Chinese University Professors: Qualities and Impact on Students. The IAFOR Journal of Education, 4(1), $123-145$.

Noor, W. (2020). Integrasi Budaya Prestasi pada Fungsi Perencanaan Pembinaan Mutu Dosen. Al-Tanzim: Jurnal Manajemen Pendidikan Islam, 4(1), 1-12.

Sallis, E. (2012). Total Quality Manajemen In Education. Yogyakarta: IRCiSoD.

Sanaky, H. A. H. (2008). Permasalahan dan Penataan Pendidikan Islam Menuju Pendidikan yang Bermutu. El-Tarbawi: Jurnal Pendidikan Islam, 1(1), 8397.

Sayidah, N., Ady, S. U., \& Supriyati, J. (2019). Quality and University Governance in Indonesia. International Journal of Higher Education, 8(4), 10-17. https:// doi.org/10.5430/ijhe.v8n4p10

Sulaiman, A., \& Wibowo, U. B. (2016). Implementasi Sistem Penjaminan Mutu Internal sebagai Upaya Meningkatkan Mutu Pendidikan di Universitas Gadjah Mada. Jurnal Akuntabilitas Manajemen Pendidikan, 4(1), 17-32.

Sumardjoko, B. (2010). Faktor-faktor Determinan Peran Dosen dalam Penjaminan Mutu Perguruan Tinggi. Cakrawala Pendidikan, 19(3), 294310.

Sururin. (2017). Peta Peringkat Akreditasi Perguruan Tinggi Keagamaan Islam: Sebuah Kajian Awal. Jurnal At-Taqaddum, 9(1), 95-112.

Wani, I. A., \& Mehraj., H. K. (2014). Total Quality Management in Education: An Analysis. International Journal of Humanities and Social Science Invention, 3(6), 71-78.

Winarsih, S. (2017). Kebijakan dan Implementasi Manajemen Pendidikan Tinggi dalam Meningkatkan Mutu Pendidikan. Cendekia: Jurnal Kependidikan dan Kemasyarakatan, 15(1), 51-66.

Yinka, E. (2015). Quality Assurance of University Education: Whose Responsibility ?. Asian Journal of Education and Training, 1(1), 8-13. 